\title{
MAL-ESTAR NA CIVILIZAÇÃO E DESASTRE TOTALITÁRIO
}

François Villa

Professor de psicopatologia, diretor-adjunto do Centro de Pesquisas Psicanálise, Medicina e Sociedade, Universidade de Paris Diderot, Sorbonne Paris Cité, Paris. Psicanalista, membro da Associação Psicanalítica da França e da Associação Psicanalítica Internacional.

Tradução Pedro Henrique Bernardes Rondon

RESUMO: O autor interroga a relação entre o desastre totalitário e a psicanálise. Será que a psicanálise, os psicanalistas, tem algo pertinente a dizer acerca da barbárie? Esta não é uma dimensão que estaria fora do nosso campo? Será que podemos afirmar que o desastre que sobreveio na cultura não teria tido senão pouca ou nenhuma consequência sobre nossa “teoria”, nossas “práticas”, nossa "arte”? Não é incrível que demos seguimento à tarefa psicanalítica como se a onda da irrupção do terror e da barbárie na cultura não tivesse abalado as quatro paredes de nossos consultórios? Estas são perguntas que este artigo enfrenta e que levam o autor a se voltar sobre a questão dos estados limites a partir de sua reflexão acerca dos efeitos psíquicos duradouros do totalitarismo.

Palavras-chave: Mal-estar na civilização, morte (nossa atitude diante da morte), psicologia das massas, totalitarismo.

ABSTRACT: Malaise in civilization and totalitarian disaster. The author cross-examines the relationship between psychoanalysis and totalitarian disaster. Does psychoanalysis, psychoanalysts, have something relevant to say about the barbarism? Isn't this a dimension which is beyond our field? Can we say that the disaster that befell the culture would not have had but little or no consequence on our "theory", our "practice" our "art"? Isn't it amazing that we follow the psychoanalytic task as if the wave of eruption of terror and barbarism in culture had not shaken the four walls of our offices? These are questions which this article is facing, and leading the author to get back on the issue of borderline states since his reflection on the lasting psychological effects of totalitarianism.

Keywords: Malaise in civilization, death (our attitude towards death), mass psychology, totalitarianism. 
$\mathrm{E}$ m Malaise dans la culture [O mal-estar na civilização], Freud retoma por sua conta um verso de uma balada de Goethe: nós não gostamos de ouvir isto... Isto, aqui, designa nossa inclinação inata para o 'mal', para a agressão, para a destruição e a crueldade (FREUD, 1930/1994, p.306). É inegável que o pensamento dificilmente reconhece a realidade dessa inclinação. E, no entanto, o desastre dos totalitarismos, em que progresso na cultura e barbárie se associaram, nos obriga a reconhecê-la. Nós não acabamos de apreender essa catástrofe que engendrou certo desespero, uma indubitável desilusão e uma decepção não menos real: o homem, nós, na verdade somos capazes disso.

Será que nós poderíamos afirmar sem hesitação que o desastre não inscreveu seus rastros em nosso corpo? Quando escrevo 'corpo', é preciso entender soma e psiquismo inextricavelmente intricados. Será que não resta a cumprir, ainda e sempre, o ato de dizer acerca dessa catástrofe que mergulhou o mundo numa perda radical de sentido e talvez tenha cavado até o fundo do espírito para semear aí a desolação? Ainda hoje aquele que tenta falar daquilo que aconteceu é ameaçado de ser tomado como suspeito... pelos outros, mas também por ele mesmo. Na nossa comunidade, isso poderia exprimir-se sob a forma de "esse não é um tema psicanalítico!"

Que relação haverá entre esse desastre e a psicanálise? Será que a psicanálise, os psicanalistas têm algo de pertinente a dizer sobre isso que aconteceu? Não será essa uma dimensão que estaria fora do nosso campo? O desastre que sobreveio na cultura não teria tido senão pouca ou nenhuma consequência sobre nossa “teoria”, nossas "práticas”, nossa "arte”? Não é inacreditável que prossigamos nossa tarefa psicanalítica como se a onda de irrupção do terror e da barbárie na cultura não tivesse abalado as quatro paredes dos nossos consultórios? E isso, ainda que um dos objetivos do totalitarismo fosse que nenhuma parede separasse o público do privado, nem se levantasse entre o servo voluntário da multidão e seu Führer? ${ }^{1}$ (BERADT, 2002, p.149). Alguém poderia objetar que é assim porque o núcleo do psíquico continua sempre o mesmo, indestrutível, e que nós fundamentalmente só temos que nos haver com os elementos constitutivos... da ordem de uma invariância muito forte, intemporais e a-históricos.

Tal "crença” seria uma ilusão tornada possível por uma operação de clivagem? O benefício disso seria poder fazer como se... do cataclismo, não houvesse nada a ouvir no tratamento e que nada se daria a ouvir sobre isso. Se fosse assim, nós teríamos que nos perguntar se verdadeiramente houve desastre, e que considerar que,

\footnotetext{
${ }^{1}$ Cf. meu trabalho sobre "Au coeur du rêve, la horde", publicado em Penser/rever, n.15, Toutepuissance, primavera 2009, Paris: De l'Olivier, p. 41-60. O Führer evidentemente remete a Adolf Hitler e também a Josef Stalin, mas sobretudo, e bem mais essencialmente à maneira como Freud descobre essa figura em "Psychologie des masses et analyse du moi" (FREUD, 1921/1991).
} 
nessa barbárie, não havia nada de inédito, de inaudito. Esse desastre não teria sido senão a repetição de uma das numerosas tragédias sangrentas sobrevindas na história. Ruído e furor na superfície do mundo, sem que isso tocasse os fundamentos nem do ser, nem do ser-conjunto dos homens. Em compensação, se pensamos que houve desastre, não podemos excluir que a ruína que resultou daí estendeu-se até o âmago do espírito, até questionar novamente a pertinência de cada um ao conjunto da humanidade.

Não reter tal possibilidade seria desconhecer até que ponto, para Freud, a psicanálise era parte integrante do progresso cultural. Era mesmo um dos fatores determinantes e era determinada, tanto em sua criação quanto em seu desenvolvimento, pela Weltanschauung científica (FREUD, 1932/1995). O tratamento e o trabalho da cultura que o caracteriza constituem contribuição à cultura, um reforço da capacidade do indivíduo para se apropriar das razões e dos interditos nos quais se apoia a existência da sociedade. Não poderia haver progresso nem na teoria analítica nem nos tratamentos sem uma determinada "concordância" entre estes e os progressos ou os impasses da cultura - na expressão trabalho de cultura, como enfatizou Nathalie Zaltzman (1998; 2007), o individual e o coletivo se combinam, no foro íntimo do ser e da cultura: a salvação e a queda de um passam conflituosamente pela salvação e pela queda do outro.

A Primeira Guerra Mundial demonstrou que as criações do homem ficam à vontade para destruir e que a ciência e a técnica que as edificaram podem servir também para anulá-las (FREUD, 1927/1994). A lição dos totalitarismos é ainda mais cruel uma vez que sabemos, sem chegar a efetivamente saber, que nos campos de concentração, os homens, como escreve R. Antelme, viram aquilo que não "deviam” ver e que não pode ser traduzido pela linguagem. Resta daí para nós uma estupefação que ainda não pôde ser traduzida por nenhum ato (ANTELME/1969). Será que consideramos suficientemente que os processos psíquicos engendrados por aquilo que foi visto - uma vez que estão longe de ser efetivamente trazidos à consciência — puderam se constituir como lembranças intensas e tenazes que, resistindo a qualquer rememoração, assombram o indivíduo e o coletivo? (FREUD, 1920a/1981, p.31). Essas "novas” marcas não teriam se tornado tão indestrutíveis quanto as mais antigas?

Não apenas não chegamos a saber qual a extensão da transformação dos espíritos e das mentalidades sob os regimes totalitários, como também não sabemos até que ponto nosso espírito e nossa mentalidade são a descendência direta de tal transformação. Essa transformação teria sido apenas transitória, efêmera? Será que vamos rejeitar sem hesitação a ideia de uma transformação irreversível e a hipótese de que a regressão que favoreceu a instauração do regime nazista tanto quanto a tornou possível, atingiu um ponto que favorece o retorno 
de alguma coisa que nunca tinha existido? ${ }^{2}$ E se isso nos parece exagerado, ao menos perguntemos a nós mesmos o que terá sido feito dos ideais culturais após o cataclismo que teve como consequência a decomposição e o desmembramento tanto do projeto civilizador quanto da personalidade psíquica.

Uma crítica poderia ser feita a mim a propósito do risco de indistinção do individual e do coletivo. Essa indistinção poderia ser, em parte, uma consequência do desastre sobre o pensamento. Uma das características do totalitarismo tem sido a negação da singularidade do indivíduo — reduzido, como o escreve Adorno, a não ser mais do que um exemplar. Resulta daí uma coalescência do individual e do coletivo cujo precipitado foi a massa totalitária. Essa contração, destruidora da subjetividade, revelou a estreita interdependência da construção e formação de um individuo com a forma tomada pela organização social. Uma das jogadas de uma saída possível dos efeitos do desastre que ainda estão em ação, seria a de reencontrar a via de uma individuação que seria outra coisa que não a via de um individualismo encolhido num recuo à autoconservação (ADORNO, 2003, p.440). Esse individualismo, para ser ouvido, sem dúvida ganharia por ser pensado como efeito possível da devastação totalitária - como seu resíduo atual. Freud abriu, em "Psychologie des masses et analyse du moi" ["Psicologia de grupo e análise do ego”] (FREUD, 1921/1991), uma reflexão sobre o mecanismo interno do individual e do coletivo, porém, a passagem do individual ao coletivo continuou obscura para nós ${ }^{3}$.

Em "Au coeur du rêve, la horde" [No âmago do sonho, a horda] (VILLA, 2009), que a revista Penser/Rêver, dirigida por Michel Gribinski publicou, tentei pensar aquilo que, no cerne do psíquico, teria podido favorecer a ascensão do totalitarismo. Quero agora refletir sobre aquilo que, após o reaparecimento vivo da horda, pôde ser modificado no psiquismo, e qual teria sido a herança disso. Vou tomar como exemplo a lição de "Actuelles sur la guerre et la mort" [Reflexões para os tempos de guerra e morte] (FREUD, 1915/1988). Para circunscrever aquilo que está para chegar, Freud retém dois efeitos da Grande Guerra: por um lado, a desilusão acerca dos progressos conseguidos pela civilização e, por outro, a modificação de nossa atitude a propósito da morte. Para interrogar as repercussões atuais da catástrofe, nossa reflexão terá por objeto esses mesmos pontos. A noção de desilusão basta para acusar o golpe que foi dado no humano e na cultura? O que é que adveio à nossa atitude em relação à morte após os assassinatos em massa cujas marcas se tentou apagar por uma segunda eliminação: a dos cadáveres?

\footnotetext{
${ }^{2}$ Leia o comentário de Nathalie Zaltzman acerca do livro de Golding, Sa Majesté des Mouches, em Zaltzman, 2007.

${ }^{3}$ Ver também PUGET J. (Eds.) Violence d'état et psychanalyse. Paris: Dunod, 2001 e VIÑAR, M. \& M. Exil et torture. Paris: Denoël, 1989.
} 
No final de "Passagèreté" [Sobre a transitoriedade], em 1915, Freud se pergunta se todos os bens, os ideais, que não foram suficientes para resistir à guerra e para nos proteger de seu cortejo de infelicidades, estão definitivamente perdidos e desvalorizados. Ele afirma que com essas perdas as coisas não vão ser diferentes do que aconteceu com as que as precederam. Ele escreve: "Vamos reconstruir tudo o que a guerra destruiu talvez sobre uma base mais sólida e mais duradoura do que anteriormente" (FREUD, 1916/1988, p.324).

Para apreender a catástrofe, nos resta o pensamento; porém... justamente a desilusão tem por objeto a capacidade do pensamento para tolerar a realidade da nossa inclinação para o mal. Antes de 1914 já havia dúvidas quanto a que o pensamento pudesse realmente enfrentar a realidade tanto das pulsões quanto do mundo. A Grande Guerra reforçou e confirmou uma quantidade de considerações nascidas da psicopatologia. Essas observações obrigaram Freud a conceber uma pulsão singular cujo alvo é nada menos do que a destruição de sua própria morada orgânica (FREUD, 1932/1995, p.189) e que denominou pulsão de morte. Esta pulsão impõe que não se faça pouco do descomedimento das exigências pulsionais e que se encare que a hostilidade profunda da pulsão a qualquer educação pode se tornar paixão da anulação... de si mesmo ou, por deflexão, do outro ou, na falta deste, novamente de si mesmo.

"Au-delà du principe de plaisirs" [Além do princípio de prazer] (FREUD, 1920/1996) nos convida a nos representar a vida ...sob o jugo de uma predisposição ao aniquilamento. Obriga-nos a pensar a obra da pulsão de morte no trabalho do pensamento. Freud reencontra aí, talvez sem se dar conta disso, uma hipótese apresentada em 1895, no "Projeto": o pensamento não visa, em primeiro lugar, a produção do pensamento, porém, antes de tudo, tenta restabelecer a identidade de percepção que permitiria a descarga e, em consequência, a extinção da pulsão e dele próprio.

O pensamento está tanto a serviço da pulsão de morte e da destruição quanto de Eros e da construção. Não é natural admitir que as tendências e os objetivos dessa pulsão não somente agem e se exprimem no pensamento, mas são também as tendências e os objetivos do pensamento. Este, como a pulsão de morte, dirige sua potência para a decomposição de toda organização, sua força visa a desfazer os laços que também contribuiu para estabelecer e que o mantêm vivo. Uma tendência no pensamento converge, cega e silenciosamente, para o retorno a esse estado anterior que, como escreve Laurence Kahn, tem a cara do inorgânico (KAHN, 2005, p.211), da vida decomposta em suas partículas mais elementares, da morte despojada de toda dimensão consoladora e reduzida a sua inelutabilidade biológica.

Só a força de Eros impõe à pulsão de morte que se abstenha à vinda da morte, e apoiar, para alcançar seu objetivo, esse desvio que a vida é para ela. 
Entretanto, não é senão para destruir os múltiplos compostos e intrigas que Eros pode construir que a pulsão de morte se intrica transitoriamente à pulsão de vida. É por obrigação que ela traz sua contribuição ao trabalho de Eros... para, no final, poder desfazê-lo melhor. Somente essa intricação atenua sua força de autoaniquilamento produzindo a deflexão da agressão em direção ao exterior, sobre objetos libidinalmente investidos. Essa derivação oferece ao pensamento a oportunidade de adquirir novas funções.

Eros impele o pensamento a participar do reencontro do objeto pré-histórico. Quando a percepção não estabelece uma identidade entre esse objeto e um objeto da realidade interna ou externa, cabe ao pensamento trabalhar para saber se é possível negligenciar as diferenças percebidas e se o objeto presente pode ser tido por idêntico àquele cuja nostalgia nos habita. O pensamento está então fundamentalmente a serviço do princípio de prazer. Mas a necessidade vai impor uma modificação de onde vai resultar o princípio de realidade. Este vai tentar dar conta, apesar do desprazer, das diferenças percebidas, e de admitir realmente sua existência. Por um lado, portanto, o pensamento está pronto, a partir de determinada semelhança, a forjar a ilusão de uma realidade conforme ao desejo, e a agir como se fosse esse o caso. Por outro lado, o pensamento afronta a verdade da ausência do objeto e da satisfação esperada e permite agir, fora da ilusão, sobre a realidade reconhecida tal como é. Existe uma débil margem, portanto, para que o pensamento não ceda à ilusão e que o homem adquira a liberdade de poder pensar e agir mesmo quando o mundo se revele decepcionante. É nesse jogo que a violência pulsional pode ser retida e que nasce o pensamento científico. O objetivo que lhe é atribuído é de nos obrigar a perceber essa realidade que existe fora de nós, independentemente de nós — inclusive quando é fonte de desprazer — e o de chegar a estabelecer uma certa coincidência entre o campo do pensamento e o campo dos atos humanos. Essa capacidade de perceber a realidade é designada por Freud como verdade e, mesmo, como amor pela verdade.

Antes da Grande Guerra a civilização parecia ter dado um passo irreversível para diante, os homens efetivamente culturais, dos quais Freud fazia parte, compartilhavam essa esperança e queriam acreditar que os progressos da ciência e da cultura avançavam juntos. Esse otimismo era temperado pelo paradoxo onde se revelava que os progressos do conhecimento científico também tinham por corolário uma perda de sentido do mundo. A conjunção dessa perda de sentido com o recuo das crenças religiosas consoladoras engendrou surda inquietude acerca do futuro, que Max Weber chamou de “desencanto do mundo” (WEBER, 1904-1905/1964) de onde resultaria um reforço da ansiedade individual e social.

Freud ligou essa perda de sentido ao fato de que o pensamento científico, ainda jovem entre os homens, sabia muito pouco sobre isso e que os homens continuavam sob o domínio das concepções religiosas. Mas isso era apenas uma transição, e com o tem- 
po o espírito científico viria a se impor e a razão aceitaria perceber a realidade da condição humana. Da luta contra o desencanto, encontramos vestígios em “Traitement psychique (traitement de l'âme)" [Tratamento psíquico (ou mental)] (FREUD, 1890/1984): a ciência, diz Freud, rejeitou apressadamente a magia das palavras, é um equívoco não ver aí senão um resto de religiosidade. A psicanálise revela que é longo o desvio por onde, de seu interior, a ciência se vê chamada à dupla necessidade de restituir à palavra uma parte da sua magia de outrora e prestar atenção à estranha espera crente que habita o homem. Para encarar o destino do homem do Iluminismo que, com muita frequência, se revelou um hipócrita da cultura que vivia acima de seus recursos psíquicos (FREUD, 1915/1988, p.137-138), devemos apelar a essas duas dimensões. Como pensar os efeitos do discurso na constituição de uma multidão e tentar dar conta dos efeitos da propaganda... sem apelar a essa magia das palavras e a essa espera crente?

O princípio de realidade introduz uma batida no pensamento que provoca alargamento da percepção da realidade e perda de ilusões. O alcance dessa abertura não deve ser superestimado. O princípio de realidade não trabalha contra Eros senão porque conformar-se apenas à lei do prazer teria como consequência a realização da pulsão de morte — isto é, a autoaniquilação. Desfazendo as ilusões, ele fragiliza o homem e o faz entrever a que ponto o mundo lhe continua estranho, fonte de uma insatisfação que o agride e chama de volta sua agressividade. Perto do caminho em direção a um acréscimo de conhecimento científico, há outros caminhos; há aquele de uma certa melancolização da existência, mas há também o de uma guerra permanente contra o mundo e contra seus semelhantes. Confrontando-nos a nossa realidade, o princípio de realidade abre igualmente o caminho para certa deflexão das pulsões em direção ao exterior. Essa derivação é uma verdadeira proteção que, no entanto, pode revelar-se mortalmente protetora.

Originariamente e sempre nós só pensamos para suprimir a razão de ser do pensamento, para suprimir a excitação dolorosa que o espicaça. Esse estímulo é o incansável trabalho das pulsões que aspiram a essa satisfação que se confunde com sua extinção. Objetivo radical e derradeira extremidade, a pior que seja para o "eu" que, no entanto, pode algumas vezes, estranhamente, brutalmente, se resolver aí, seja quando, sentindo-se abandonado pelo mundo, ele abandona a si mesmo, seja quando tendo, por superestimação, substituído o ideal do eu pelo objeto, está pronto a aniquilar-se no objeto para o conservar, compondo com ele um todo único.

Não seria no lugar exato do fracasso da pulsão de morte que o pensamento surgiria? Sua razão primeira seria disfarçar esse fracasso; seu desenvolvimento, a consequência de sua incapacidade de ser suplemento eficaz da pulsão de morte. O pensamento, desesperado por seu fracasso, se engaja nas suas primeiras 
complicações a fim de servir ao seu primeiro mestre nos melhores momentos. Entretanto, fazendo isso, ele sai do regime de imediatismo para passar ao de adiar; descobre as lógicas da temporização e da temporalização. O pensamento se põe a esperar. Mais do que isso: se põe a acreditar no poder da espera. O aparecimento da espera crente, sem dúvida, é contemporâneo do primeiro fracasso do pensamento. Nós o encontramos no cerne do maior desamparo - seu provável local de nascimento. Ele continua aí ativo, e leva o homem, cheio de esperança, a acreditar que deve bem existir alguém ou alguma coisa a quem ou a que poder entregar-se em confiança. Há nessa espera uma face cheia de esperança que as contingências da vida tanto podem satisfazer quanto frustrar. Quando sobrevém a decepção, aparece outro hóspede permanente do homem: a espera ansiosa. Ninguém vai ficar surpreendido de que a espera seja igualmente cheia de ansiedade, talvez mesmo de angústia de que não é espera de esperança, que seja igualmente habitada pelo desejo nostálgico e pelo ódio de tudo o que se oponha a isso. A espera tem tendência a condensar-se num objeto de crença e sobre esse objeto, ao qual o indivíduo pode se fixar compulsivamente. De indeterminada que era, a espera se vê então determinada exclusivamente pelo objeto cuja sombra se abateu sobre ela. O eu pode, algumas vezes, se tornar o lugar de uma paixão odienta contra tudo o que contesta a supremacia do objeto escolhido. Os homens não hesitam em se entregar, em nome dos ideais que o habitam, aos comportamentos mais irracionais com uma credulidade e uma submissão que ultrapassam o entendimento.

Nascido para desaparecer tão logo se cumprisse sua tarefa original, o pensamento se põe a durar e, animado pela espera crente, dedica sua atenção aos mundos externo e interno a fim de encontrar aí tanto objetos de acordo com o princípio de constância quanto materiais que vão, o mais depressa possível, apoiar a pulsão de morte. Permanecendo assujeitado à pulsão de morte, o pensamento se engaja no movimento evolutivo aberto pelo insucesso da pulsão. O conflito entre as duas pulsões dilacera o pensamento sem parar. Por um lado, tenta responder às necessidades da vida abolindo as urgências a que o homem está submetido e, fazendo isso, visa sempre seu próprio fim. Por outro lado, o pensamento também mudou de razão, tornou-se raciocinante, talvez mesmo razoável e se entregou, como segunda razão de ser, a favorecer o desvio que a vida constitui. Como Pierre Fédida (2001) já tinha observado, o pensamento, que deveria ter permitido o retorno ao inanimado, deve agora contentar-se de conseguir desanimar um pouco o caldeirão das pulsões, deve dessexualizar para manter a vida animada apenas o quanto baste para torná-la viável. Assim, os guardiões da vida são também os agentes da morte. 
Mesmo sabendo isso, Freud confia no pensamento. Em 1910 (FREUD, 1910/1977), em 1927 (FREUD, 1927/1994) ${ }^{4}$ e em 1933 (FREUD, 1932/1995), ${ }^{5}$ ele afirma que o retorno da verdade certamente não leva ao seu reconhecimento imediato, mas que sua força é tal que, com o tempo, mesmo "a [verdade] mais chocante sempre vai acabar sendo percebida e se impondo, uma vez que os interesses com que se choca, e as emoções que desperta, tenham esgotado sua virulência” (FREUD, 1910/1977).

Do real só queremos ver aquilo que venha a responder a desejos sem levar em consideração a verdade. Aquilo que chamamos realidade não é, à maioria das vezes, senão uma neorrealidade com que a substituímos. Toda organização psíquica exprime uma perda de realidade (FREUD, 1924/1992), mas o núcleo das ilusões contém tanto as crenças primitivas quando a verdade que elas ocultam. A verdade pode ser ouvida pela suspensão ou pela atenuação do recalcamento. Paradoxalmente, essa suspensão é “facilitada” pela pulsão de morte. Atacando as obras de Eros, a pulsão de morte reabre a porta, no pensamento, para a espera indeterminada. Posto em movimento por essa espera, o pensamento pode franquear, mais além da ilusão, o retorno do recalcado, e dar uma oportunidade para a verdade.

O retorno do recalcado é condição necessária, mas não suficiente, e não dispensa o esforço que falta fazer para reconhecer a verdade tornada novamente perceptível. Sem esse esforço psíquico o retorno vai engendrar antes uma regressão do que um progresso. Nesse caso, o predomínio seria dado novamente ao mecanismo da projeção sob a forma de agires individuais ou coletivos. O retorno da verdade põe a nu os papéis mínimos do homem no vasto universo, e da razão em relação às forças pulsionais. Suportar essa verdade desagradável é o que poderia fazer do homem um ser verdadeiramente sem religião.

Postular que a violência é inerente à própria natureza do homem questiona suficientemente a esperança na razão para que surgisse em Freud um momento de desesperança, que ele superou, em "Por que a guerra”, em 1933, recorrendo a

\footnotetext{
4 "Podemos bem enfatizar muitas vezes que o intelecto humano não tem forças em comparação com a vida pulsional humana, e fazer isso com razão, mas há, apesar de tudo, alguma coisa particular nessa fraqueza; a voz do intelecto é fraca, mas não se cala enquanto não se fizer ouvir. Depois de ter suportado muitas vezes não ser ouvida, termina por conseguir. Esse é um dos raros pontos em que temos razão de ficar otimistas quanto ao futuro da humanidade, mas em si mesmo não deixa de ter significação" (FREUD/1995).

5 “É nossa maior esperança para o futuro que a inteligência — o espírito científico, a razão - com o tempo chegue à ditadura na vida psíquica do homem. A essência da razão em nós é uma garantia de que não vai deixar de atribuir às moções afetivas humanas, e àquilo que é determinado por estas, o lugar que lhes cabe como laço unificador mais forte entre os homens e vai abrir caminho para novas unificações. Tudo o que se opõe a tal desenvolvimento, como a proibição de pensar devida à religião, põe em perigo o futuro da humanidade" (FREUD, 1927/1995).
} 
uma hipótese de tipo darwiniano. O processo de desenvolvimento cultural se desdobrou numa escala de tempo já tão longa que é possível que tenha gerado efeitos comparáveis à domesticação dos animais. Modificações corporais e transformações psíquicas se seguiriam, e determinados deslocamentos dos alvos pulsionais exigidos pela cultura, então se tornariam obrigações biológicas internas transmissíveis às gerações seguintes. Originariamente nós não pensamos senão em modificar o mundo para que ele seja o mais conforme possível aos nossos desejos, e é verdade que o que acontece ao pensamento, e no pensamento, tem efeitos na cultura e na sociedade. Não é concebível pensar que, em compensação, esse mundo nos modificaria?

Na passagem do individual ao coletivo a relação com a realidade e com as exigências pulsionais é um lugar de discórdia entre o indivíduo e o coletivo. As exigências culturais impõem suportar certo nível de desprazer num aparelho psíquico cuja principal função é evitá-lo e que, para se defender disso, está pronto a sacrificar não somente a verdade, mas também muitas outras coisas. A sobrevivência da cultura impõe uma restrição do direito à violência individual. A sobrevivência do indivíduo reclama a possibilidade de que a agressão possa encontrar satisfação no mundo externo. Como Freud observou em 1933, “parece efetivamente que nos seja preciso destruir outras coisas e outros seres [...] para nos preservar da tendência à autodestruição" (FREUD, 1932/1995, p.188). Não é apenas a necessidade de amor que leva em direção aos outros homens, é também a necessidade de destruir — inclusive destruir outros homens — para sobreviver. É a partir desse conflito que adquire sentido a hostilidade do homem contra todas as instituições de que a cultura se dota para se defender do autocratismo individual, e que se impõe a ideia de que a guerra parece praticamente inevitável. Paradoxalmente, dando livre curso ao emprego exterior da pulsão de morte, esta participa da obra autoconservadora de Eros.

A guerra mostra que as exigências da cultura são muito mais ideais impostos por um superego do que uma ética pessoal forjada por elaboração psíquica. Basta que os povos e os estados que os representam (FREUD, 1915/1988, p.141) relaxem suas exigências, passando da paz à guerra, para que os indivíduos revelem que, na realidade, não tinham se elevado tão alto quanto se acreditava, e que essencialmente se mantinham numa dependência e numa acomodação aos ideais e aos líderes dominantes. A Grande Guerra mostrou a persistência do primitivo no homem, e levou Freud a propor que o homem guarda em seu sangue o prazer do assassinato, próprio a essa linhagem infinitamente longa de assassinos, da qual descendemos (FREUD, 1915/1988, p.151). Revelou com ênfase que um estado de organização psíquica que parecia ter desaparecido subsiste sempre na realidade psíquica e que, em determinadas circunstâncias, pode readquirir, no presente, sua forma predominante. Freud explica que, em compensação, acontece que o estádio abandonado 
em seguida à regressão não pode ser reativado e reinstaurado — portanto, nem tudo é indestrutível no psíquico.

Antes dos totalitarismos, o laço entre a coisa psíquica e a coisa cultural era árduo, mas se torna ainda mais penoso depois da viagem além do princípio de prazer, num mundo em que é a pulsão de morte que conduz a dança da vida e que cava o hiato entre os desenvolvimentos individual e cultural.

Freud fica estupefato com sua hipótese. Ora comunica que é difícil acreditar nisso, estar convencido disso. ${ }^{6}$ Ora ele se lembra de sua própria defesa contra a ideia de uma pulsão de destruição quando ela emergiu pela primeira vez, em 1912 (FREUD, 1930/1994, p.306). Ora, ainda, se espanta de ter "podido deixar de ver a ubiquidade da agressão e da destruição não eróticas, e negligenciar quanto a atribuir-lhes o lugar que lhes cabe na interpretação da vida” (loc. cit.). É que, reconhece, é bem difícil aceitar a inverossímil hipótese de que a destruição faz parte da constituição humana, e fazer dela a causa do movimento evolutivo. Isso não apenas ataca a representação idealizada do homem, mas obriga também a pensar no desacordo existente no interior do indivíduo, no interior do coletivo, e entre eles. Porém, “infelizmente”, escreve Freud, “aquilo que a história nos relata e aquilo que nós mesmos vivemos justificam antes o juízo segundo o qual a crença na 'bondade’ da natureza humana é uma dessas ilusões malvadas [que] na realidade só trazem prejuízo”.

Para sustentar sua hipótese, Freud convoca a história e aquilo que ele próprio viveu, mas logo cai em si e afirma que é principalmente sobre a base de considerações clínicas e não “por causa de relatos da história e da experiência da vida [que ele passou a] preconizar a hipótese de uma pulsão de agressão e destruição no ser humano” (FREUD, 1932/1995, p.186). Freud não se apressa um pouco a dispensar esses dois convidados: a história, da qual a Grande Guerra faz parte, e sua própria experiência de vida, para só manter a referência à experiência psicanalítica. Não esqueçamos o lugar que as neuroses de guerra ocupam na arquitetura de "Além do princípio de prazer".

Não estaríamos em presença de uma dessas denegações onde se trai que a gênese como a genealogia dos nossos modos de pensar nos são opacos: sempre o esquecimento já passou por aí? Não será a expressão de um recuo-fuga que compartilharíamos muito à vontade? Na nossa vez, nós talvez o façamos dispensando frequentemente depressa demais tanto a história quanto nossa experiência pessoal. Depressa demais porque, entrincheirando-nos na esfera do individual, isso nos dispensa, de acolher o enigma das relações inextricavelmente amarradas entre o individual e o coletivo.

Freud escreveu numa época que certamente é a do desencanto e da desilusão, mas onde se estava longe de poder pensar ou imaginar o triunfo do mal no mundo. O mundo ainda não sabia dos recursos demoníacos de uma multidão entusiasta agrupada à volta de um Führer... Como o observa H. Arendt, os homens

\footnotetext{
6 "Eu próprio não estou convencido [...] das hipóteses desenvolvidas aqui”, "não sei em que medida acredito nisso" (FREUD, 1920/1996, p. 333).
} 
então não tinham que superar "nossa real resistência a encarar que [...] o mal exerce em nossa época uma força mórbida de atração" (ARENDT, 2002, p.613). Essa atração é que foi atuada.

Eu me alinho entre aqueles ${ }^{7}$ que a inverossimilhança da hipótese da pulsão de morte não impede de avançar, e que a pensam necessária para acusar o golpe que foi imposto ao homem pelo desastre... Porém, indiscutivelmente é muito desagradável fazer as pazes com o pensamento de tal pulsão, reconhecer e assumir plenamente sua força em nossa vida cotidiana.

Para Freud, a Primeira Guerra, como todas as outras, impôs acreditar na morte em razão do acúmulo diário de mortes. A morte não podia mais ser rebaixada, pelo pensamento, do nível de necessidade ao de casualidade. A desilusão foi grande, mas não suficiente para que o homem temesse ter caído fora da humanidade. Quanto à guerra seguinte, tudo se passou de outra maneira. Esta não foi uma guerra comum, porque a lógica do regime nazista era a vitória ou a morte. No momento da derrota, não havia inimigos, no sentido tradicional do termo, para assinar o tratado de paz. Havia, de um lado, os vencedores e, do outro, os inimigos da humanidade que não se sentiam autores nem culpados pelo crime cometido. Houve derrota dos nazistas, mas teria isso sido suficiente para extirpar o veneno instilado no psiquismo de todos os homens? O mal que atingiu a espécie humana a partir de seu interior terá sido definitivamente vencido? (VILLA \& WEIL, no prelo em 2010).

Essa guerra não foi outra repetição impondo que se acredite na morte. Ela obriga tragicamente a pensar, conforme escreve Adorno (2003, p.449), que há algo pior do que a morte - não tanto por causa do maior acúmulo de mortes quanto pelo desaparecimento maciço, por destruição dos cadáveres dos exterminados. A Segunda Guerra, mais do que um acúmulo de mortes, gerou um acúmulo de desaparecimentos...

Na Primeira Guerra os progressos da técnica tinham aumentado consideravelmente os meios de matar à distância. Porém, apesar disso, a morte envolvia essencialmente o enfrentamento que obrigava a considerar a morte encarando a si mesmo. Segundo Adorno, antes do totalitarismo, o que tornava a morte suportável aos homens era o sentimento de sua unidade épica com uma vida satisfatória (Loc. cit.). Como observa Laurence Kahn, nós ainda estávamos na lógica posta em ação em “Totem e tabu”, a lógica de um "assassinato cometido na finalidade de destino do pacto de irmãos [fundador] do pacto social. [Esse assassinato fica] organizado pelo relato épico [que] contando, recalca o ódio em proveito da nostalgia e do interdito" (KAHN, 2005, p.228).

Com além do princípio de prazer, a morte à qual o anorgânico remete, visado pela pulsão de morte, não é mais aquela produzida por um assassinato, mas

\footnotetext{
${ }^{7}$ Dentre aqueles que a inverossímil pulsão de morte não impede de avançar, eu já citei N. Zaltzman, e vou acrescentar aí A. Green, a) "pourquoi le mal”, Nouvelle Révue de Psychanalyse, 1988, n.38, p.239-261, b) “Pourquoi les pulsions de destruction ou de mort?”, Fédida, P. Humain/ Déshumain, Paris: PUF, 2007; Kahn, L. Faire parler le destin. Paris: Klincksieck, 2005.
} 
no máximo a que resulta do "assassinato" de si mesmo por impossibilidade de dominar a pulsão. A morte não é mais aquela que se dá ou que se recebe, mas aquela que cada qual leva dentro de si e que carrega consigo a vida por não poder vir imediatamente. É uma morte por causas internas, morte impessoal, resultante de nossa incapacidade de eliminar nossos dejetos. Essa morte não remete ao problema intelectual que a morte impõe ao vivo, por causa da ambivalência, quando ele está de pé junto ao cadáver de um ente querido ou conhecido. A morte do assassinato tem rosto humano, a da pulsão de morte remete a uma massa informe, inanimada e sem rosto.

A vontade dos regimes totalitários de suprimir a morte e os mortos anda de par com aquela não tanto de interditar o pensamento, mas de torná-lo impossível. Nesses regimes — esse é um princípio fundamental — não há senão um pensamento, o do Führer. Aí, onde existe tal mestre, a verdade e o pensamento que a poderia acolher, estão banidos. Quem quer continuar a pensar, é o inimigo. O sujeito ideal do reino totalitário é o homem devastado: um homem que vive sob o império do cinismo e da credulidade.

O homem se afastou bastante dessa época originária em que, segundo Freud, a substância viva se recriava sem cessar e morria com facilidade (FREUD, 1920b/1996). Já faz muito tempo que a morte não lhe é mais fácil. No massacre de milhões de pessoas por uma administração impessoal, a morte não surge como algo que tem um lugar no curso de uma vida que interrompe. Adorno afirma que o fato de que não é mais um homem que é assassinado e morre, mas sim o exemplar, tinha necessariamente que afetar a maneira de morrer daqueles que escaparam desse assassinato, e dos que descendem destes, isto é, nós.

Freud observa em 1915 que fora do mundo da ficção, torna-se difícil encontrar homens que se ouvem ao morrer e, o que importa mais, que conseguem mesmo matar um outro num ato do qual se reconhecem autores (FREUD, 1915/1988, p.145). É ainda mais difícil encontrar tais homens hoje em dia. À maior parte do tempo, quando um homem se torna criminoso, é para tentar escapar do sentimento de culpa inconsciente. Parafraseando Freud, ele é condenado para escapar a esse sentimento que poderia, caso contrário, conduzi-lo à autodestruição. Essa irrealidade aumentada da morte, esse não saber mais nem morrer nem matar, não depende de uma incapacidade ou de uma moral pessoal. Constitui o fato de uma sociedade que continuou e se desenvolveu a partir desse mundo onde o homem se tornou supérfluo (ARENDT, 2002), onde se tornou apenas um exemplar (Adorno, 2003), onde foi reduzido a não ser mais do que o lixo do mundo (ANTELME, 1969).

Entretanto, será que o homem pôde se tornar essa coisa sem que isso arruinasse de maneira duradoura os fundamentos do ser? Será que podemos desconhecer a terrível pergunta de Adorno: depois de Auschwitz, será que ainda se pode viver, será que ainda temos esse direito? 
A vergonha do sobrevivente é um afeto cujo potencial contagioso é terrível - a clínica nos fez descobrir mais de uma vez os estragos que causa. P. Lévi enfatiza o caráter indelével da ofensa feita ao humano, a vergonha só pode mesmo "se espalhar como uma epidemia. É uma fonte inesgotável de mal” (LÉVI, 1966, p.15). Para N. Zaltzman, essa vergonha "é uma ferida da qual ninguém pode se refazer sozinho” (ZALTZMAN, 1998, p.27). Ela assinala um momento em que se deixa de fazer parte do conjunto da humanidade e, para ser superado, exige que seja reinstaurado um pacto de afiliação à espécie. A vergonha se transmite porque os sobreviventes não podem senão apelar necessariamente ao outro humano para tentar reinstaurar esse pacto. ${ }^{8}$

No curso de uma regressão podem produzir-se fenômenos de despersonalização, de desidentificação, mais raramente de não pertencimento ao conjunto da humanidade. Freud postula que a horda primitiva é um princípio ativo e atuante no cerne do psiquismo que visa ao seu reaparecimento vivo no mundo. Não deveríamos nós considerar que, nos totalitarismos, a tendência ao reaparecimento da horda se cumpre bem além da nostalgia ambivalente pelo pai da horda primitiva? A hipótese de Nathalie Zaltzman acerca de uma pós-história nos é preciosa para avançar (ZALTZMAN, 2007, p.27). Essa pós-história surge de uma ruptura para com a história que a engendrou. Sob determinadas circunstâncias se produziria na cultura uma regressão aos estados mais primitivos do psíquico que então se veriam remanejados. O que viria a surgir desse processo não seria tanto a repetição de uma forma que já existiu, mas a produção de uma neo-história que se exprime sob a forma de uma neoformação social. O totalitarismo seria uma dessas neoformações. Um dos resultados desse processo seria, no coletivo e para o indivíduo, um recurso maciço aos mecanismos da clivagem e da projeção. Um dos efeitos disso seria a desolação do homem onde os próprios fundamentos da identificação humana e a aptidão cultural dos homens para estar juntos se se veem atacados.

A reflexão de L. Kahn provém da mesma inspiração quando ela se pergunta se, desde o assassinato de massa, nós não seríamos obrigados a pensar a origem e o destino da comunidade e do cultural de outro modo que não a partir apenas do assassinato do pai da horda. Desde o "reaparecimento" da horda no presente, desde o totalitarismo como neoformação, não sobreviria um efeito de a posteriori que remanejaria nosso ponto de vista acerca da origem e de nossa posição subjetiva?

O que teria podido advir desde a ocasião em que a horda não é mais apenas a de “Totem e Tabu”? (FREUD, 1913/1998) Desta última, os homens poderiam

\footnotetext{
${ }^{8}$ Acerca da vergonha, é preciso citar também os trabalhos de Cl. Barazer, "Hontes sans issues", em Documents et débats, Bulletin de l'Association psychanalytique de France, n. 52 e "Ulysse nu et couvert de boue", in Revue Française de Psychanalyse, t. LXVII, n.5, 2003, Paris: PUF.
} 
escapar pelo assassinato coletivo do pai primitivo a partir do qual um pacto fundador se estabeleceria entre indivíduos diferenciados. Do assassinato maciço da multidão totalitária nenhuma saída é possível por individuação. Cada indivíduo participa anonimamente, de maneira impessoal, de uma máquina que, a cada vez, realiza friamente, metodicamente, industrialmente, o aniquilamento de centenas, de milhares de indivíduos coisificados. É um assassinato que ignora tanto quem mata, quanto quem é morto, e o que é morto. É somente a realização de um trabalho. É um assassinato que se cumpre friamente, sem estado de espírito, sem culpabilidade - talvez mesmo sem vergonha. Não é mais do que a realização de um trabalho. Trata-se aí ainda de um assassinato do qual poderíamos nos apropriar através de um relato fundador, de um assassinato do qual poderíamos reconhecer-nos como autores? Aliás, é preciso isso?

Adorno observa que o aparecimento de "uma nova lógica da morte não deixa espaço para nenhuma esperança de uma futura reconstrução dos ideais”, e que isso "significa que o indivíduo [...] como espécime da espécie humana perdeu a autonomia graças à qual podia realizar o gênero humano”. Essa perda se manifesta no fato de que muitos são aqueles que, tendo vivido a experiência totalitária, observam ter sido habitados pelo sentimento de não estar verdadeiramente presentes, de realmente não ter tomado parte naquilo que acontecia, como se absolutamente não fossem eles próprios, mas sim uma espécie de observadores frios, eles não estavam lá (ADORNO, 2003, p.439).

Vou me apoiar nessas observações e na insistência, no meu relato, de termos como irrealidade, estupefação, não pertencimento, impessoalidade, anonimato, superfluidade, desolação, perda, para apresentar uma hipótese que hesito quanto a apresentar. Desse conjunto se depreende um quadro clínico que lembra ou a neurose traumática ferencziana, ou essas patologias que dizem que são novas e são chamadas de estados limites, borderline, casos limites. Trata-se de falsa semelhança, ou haverá alguma concordância real a estabelecer entre esses dados?

Essas organizações psíquicas revelam uma fragilidade na constituição do narcisismo. Isso se exprime por alterações arcaicas da constituição do eu e da personalidade psíquica que têm como consequência em vez de problemas edipianos e conflitos libidinais, problemáticas pré- ou ante-edipianas, e distúrbios identitários. Nessas doenças da alma predominam sentimentos de inexistência, sensações de insignificância, a impressão de ser informe, indiferenciado, e de não ter verdadeira autonomia. Esses pacientes experienciam o sentimento ora de existir sem viver, ora de viver sem existir, e duvidam que sejam humanos.

Para álbuns colegas o que é novo não são essas patologias, mas seu tratamento que os desenvolvimentos e progressos de nossa teoria tornaram possível. Outros veem aí a expressão psíquica das formas atuais do mal-estar na cultura, de uma crise da função paterna que se teria enfraquecido. Menos numerosos são aqueles 
que consideram articular esse aspecto de nossa clínica ao desastre. Laurence Kahn tentou fazer isso em Faire parler le destin (KAHN, 2005).

Muitos de nós se voltam, algumas vezes apaixonadamente, para a pesquisa frenética do acontecimento traumático real, ou da falência do ambiente familial primitivo, que seriam sua causa etiológica. Voltam, portanto, a uma teoria da causa essencialmente externa e não questionam o que seria inerente àquele que sofre. Vou tentar não cair numa alternativa em que as causas endógenas se opõem exclusivamente às exógenas. Meu ângulo de ataque é o velho postulado freudiano de que toda obrigação, antes de se fazer interna, foi externa (FREUD, 1915/1988, p.135). Não será preciso alinhar os efeitos do totalitarismo na categoria de uma dessas obrigações externas, e essas formas patológicas não resultariam da interiorização dessa obrigação? Desse ponto de vista, estaríamos diante do equivalente simétrico, no psiquismo, dos efeitos do desastre na cultura.

A solução de continuidade introduzida pelo totalitarismo na história do mundo não terá provocado uma ruptura impossível de suturar na trama cultural, deixando aí um furo cujos bordos ainda não descrevemos o bastante? O mundo teria entrado, como propõe Eva Weil, num período de latência (WEIL, 2000) do qual não sabemos como sair nem que modificações terão resultado daí. Essas novas patologias revelariam aquilo que opera no coração de todo homem: o abalo, pelo desastre, do alicerce fundador do coletivo a partir do qual pode se introduzir o processo de individuação que faz, de cada um, um ser diferenciado e singular.

A busca desenfreada de um traumatismo individual, de uma falência do ambiente, se substituiria ao reconhecimento de que a ausência e a impossibilidade de uma representação coletiva do desastre tem seu equivalente simétrico no psíquico. Será que podemos rejeitar sem examinar que uma modificação do isso tenha podido se produzir, engendrando tanto o remanejamento das marcas anteriores quanto a constituição de novas marcas? Se se revelar pertinente, tal hipótese teria uma consequência sobre os processos de identificação, ${ }^{9}$ porque os fundamentos comuns da comunidade teriam conhecido tanto internamente quanto externamente, uma variação imperceptível para aqueles que são seus portadores. Essa seria a consequência de que aquilo que foi visto nos campos de concentração, não podendo ser traduzido, não chega a se constituir num relato capaz de acolher o desastre. A desestabilização dos ideais confrontaria cada indivíduo a se constituir a partir também do encontro desse furo no coletivo. Teria que se prender novamente ao conjunto humano a partir da brecha deixada no coração do mundo pelo aniquilamento totalitário do qual ele já seria, ao mesmo tempo, portador. Essa brecha resulta da experiência da desolação, dela se engendra uma solidão onde cada qual é remetido infinitamente somente a si

\footnotetext{
${ }^{9}$ Sabemos que, para Freud, no processo identificatório, cada qual vai ou se apoiar nos objetos do ambiente ou buscar, no isso, as marcas deixadas pela experiência de nossos ancestrais.
} 
mesmo, como único e exclusivo fim. Todo homem tem, hoje em dia mais do que ontem, o encargo de ter que justificar sua existência - correndo o risco de se tomar por uma mônada.

$\mathrm{Na}$ falta de levar suficientemente em conta que a constituição de uma personalidade psíquica depende não apenas do estado do mundo que a cerca, mas também das marcas dos estados anteriores do mundo das quais é portador, nós viríamos a personalizar exageradamente a pequena história individual. A dimensão heroica, envolvida pelos relatos da experiência clínica com esses pacientes, evidenciaria então um entrincheiramento autocrático.

O meu discurso inteiro é assombrado por uma inquietação. Não estaremos superestimando a indestrutibilidade do psíquico? Os traços mnésicos é que são indestrutíveis. Os processos e os destinos de seus produtos, em compensação, são destrutíveis. O psíquico pode ser atingido pela destrutividade, pela do mundo e por aquela de que é portador. As condições de possibilidade do psíquico, das quais a cultura faz parte, podem ser destruídas ou alteradas. Temo que sejamos ainda mais levados a essa subestimação quando nos recusamos a levar em consideração as inverossimilhanças de nossa teoria. Adorno as leva mais a sério do que nós, às vezes, o fazemos, quando escreve que "da psicanálise, somente seus exageros são verdadeiros".

Será que não é tempo ainda de levá-las a sério? Não haverá nesses exageros um material que ajudaria a pensar um pouco mais os efeitos do desastre? A teoria psicanalítica dispõe, talvez, de recursos que ainda desconhecemos e que nos permitiriam enfrentar o real do mundo contribuindo mais para o trabalho da cultura. Situando-nos em tal perspectiva, estaríamos nos inscrevendo nessa cadeia histórica e cultural da qual cada qual é apenas um elo. Essa cadeia, desde sempre o homem mostrou que tinha o desejo de romper para não ser senão seu próprio fim. O totalitarismo a atacou mais do que nunca. Nós esperamos, mas a esperança, conforme escreve Benjamin, só nos foi dada para os desesperados (BENJAMIN, 2000, p.395). Esperamos, portanto, que essa cadeia não tenha sido quebrada e continue sendo o lugar onde pontualmente sobrevenham essas variações ínfimas que constituem a deriva infinita, não dos continentes, mas da vida da qual somos apenas expressão efêmera que a cultura tenta fazer perdurar além da morte individual. ${ }^{10}$

\footnotetext{
${ }^{10}$ Sem verdadeiramente acreditar que possam ser levantados os mal-entendidos que ficaram evidenciados numa parte da discussão que se seguiu à apresentação deste texto, vou explicar melhor alguns pontos. Neste texto, a palavra Schoah está ausente, esta é uma opção pensada e deliberada. Aquilo que chamo de desastre, catástrofe, cataclismo, com certeza inclui a solução final, o projeto de exterminar o povo judeu, isto é, todos os judeus... A Solução final está, com certeza, nos princípios do totalitarismo nazista (esse projeto está presente de maneira explícita desde Mein Kampf), porém, nessa ideologia, o judeu representa bem mais do que o povo judeu. "O ódio ao judeu” é, como vários autores observaram, ódio à cultura, ódio à incompletude e às limitações humanas. Freud observa que no mundo do ideal ariano, o judeu tem um papel de deslastre
} 


\section{REFERÊNCIASS}

ADORNO, T. Dialectique négative. Paris: Petite Bibliothèque Payot, 2003.

ANTELME R. (s/d) Lignes, n.21, p.96-97.

(1969) L'espèce humaine. Paris: Gallimard.

ARENDT, H. (2002) Les origines du totalitarisme. Eichmann à Jérusalem. Paris: Quarto, Gallimard.

BARAZER Cl. (2003) Ulysse nu et couvert de boue. Revue française de Psychanalyse, tome LXVII, n.5, Paris, PUF.

BENJAMIN, W. (2000) "Les affinités electives". In: Oeuvres I, trad. M. de Gandillac, P. Rush, R. Rochlitz. Paris: folio.

BERADT, Ch. (2002) Rêver sous le III Reich, trad. P. Saint-Germain. Paris: Payot.

FÉDIDA, P. (2001) Des bienfaits de la dépression. Éloge de la psychothéperapie. Paris: Odile Jacob. (2007) Humain/Déshumain. Paris: PUF.

FREUD, S. (1890/1984) Traitement psychique (traitement de l'âme), trad. M Borch-Jacobsen, P. Koeppel e F. Scherrer. In: Résultats, idées, problems, t. I. Paris: PUF.

econômico. Em “Moisés e o monoteísmo” (FREUD, 1939, p.184-185; 243) Freud afirma que o ódio contra o povo judeu tem sua fonte no fato de que o reconhecimento do assassinato do pai, que está na origem do cristianismo, não se cumpriu totalmente e deu lugar a um travestimento em que a responsabilidade pelo assassinato foi atribuída principalmente ao povo judeu acusado de deicida. Desse ponto de vista, o ódio ao judeu é expressão da recusa de reconhecer de maneira efetiva aquilo que está no fundamento do monoteísmo. Após o extermínio em massa, como L. Kahn observa, é necessária outra medida para pensar a estupefação:"não porque a culpabilidade transmitida imemorialmente, geração após geração, encontraria no ódio antissemita desse tempo o termo monstruoso de sua expiação. Entretanto, uma vez que de súbito a eliminação dos Judeus revela ao Ocidente como indefectivelmente ele odeia, tão imemorialmente quanto a transmissão, algo nele mesmo: não alguma coisa fora dele, mas algo nele, o próprio núcleo de sua civilização, ao mesmo tempo origem da cultura e genealogia do espírito (Kahn, 2005, p.228). É esse ódio que os totalitarismos realizam. Sua obra e seus efeitos eu chamo de desastre, catástrofe, cataclismo. O recurso à palavra desastre se impôs a mim fora de qualquer referência consciente a L'écriture du desastre, de M. Blanchot - e é por isso que não faço referência a ele e, até este dia, não questionei a dívida que meu discurso poderia ter para com esse livro cuja leitura me perturbou e constitui acontecimento importante em minha vida. Por outro lado, é indubitável que minha reflexão se defronta com o paradoxo que Maurice Blanchot destaca em L'entretien infini, quando medita acerca de L'espèce humaine de Robert Antelme (Antelme, 1969, p.192): "O homem é o indestrutível e [...], no entanto, pode ser destruído". Uma das tarefas atuais do pensamento não seria a de ter que considerar, ao mesmo tempo, por um lado, uma indestrutibilidade da espécie, uma resistência a perseverar em sua unidade indivisível além da barbárie (Antelme) e, por outro lado, uma perda da capacidade do indivíduo de realizar o gênero humano (Adorno). Após os totalitarismos, é possível que o mal-estar na cultura tenha conhecido tal exacerbação que a palavra mal-estar tenha se tornado um eufemismo que esconderia de nós que hoje em dia estamos além do mal-estar e que, consequentemente, estamos condenados a pensar na tensão entre essas duas proposições e a suportar profunda e essencial intranquilidade. Abril de 2010. 
(1895/2007) “Projet d'une psychologie”. In: Lettres à Wilhelm Fliess, 1887-1904, Trad. F. Kahn e F. Robert. Paris: PUF.

(1910/1977) "Perspective d'avenir de la thérapeutique analytique". In: . La technique psychanalytique, trad. A. Berman. Paris: PUF.

(1913/1998) “Totem et tabou”, trad. J. Altounian, a. Bourguignon, P. Cotert, A. Rauzy, com a colaboração de F. Baillet. In: Oeuvres completes - Psychanalyse, t. XI. Paris: PUF.

. (1915/1988) "Actuelles sur la guerre et la mort". In:

Oeuvres completes - Psychanalyse, t. XIII. Paris: PUF.

. (1916/1988) "Passagèreté". In: Euvres complètes, XIII. Paris, PUF. . (1920a/1981) "Au-delà du principe de plaisir", trad. J. Laplanche e J. B. Pontalis. In: Essais de psychanalyse, Paris: p.b. Payot.

(1920b/1996) “Au-delà du principe de plaisirs", trad. J. Altounian, A. Bourguignon, P. Cotet, A. Rauzy. In: Euvres completes, Psychanalyse, t. XV, 1916-1920. Paris: PUF.

. (1921/1991) "Psychologie des masses et analyse du moi", trad. J. Altounian, A. Bourguignon, P. Cotet, A. Rauzy. In: . Euvres complètes, Psychanalyse, t. XVI, 1921-1923. Paris: PUF.

. (1924/1992) "La perte de la réalité dans la névrose et la psychose", trad. J. Doron, R. Doron. In: Euvres completes, Psychanalyse. t. XVII. Paris: PUF, p.35-41. . (1927/1994) “L'avenir d’une illusion”. In: Euvres complètes, Psychanalyse, t. XVIII, 1926-1930. Paris: PUF.

(1930/1994) "Le malaise dans la culture", trad. P. Cotet, R. Laine, J. Stute-Cadiot. In: Euvres complètes, Psychanalyse, t. XVIII, 19261930, Paris PUF.

. (1932/1995) "D’une vision du monde" de Nouvelle suite des leçons d'introduction à la psychanalyse, trad. J. Altounian, A. Bourguignon, P. Cotet, A. Rauzy, R.-M Zeitlin. In: . Euvres complètes, Psychanalyse, t. XIX. Paris: PUF.

. (1939/2010) "L'homme Moïse et la religion monothéiste", trad. J Althounian, P. Cotet, P. Haller, Ch. Jouanlanne, R. Lainé, A. Rauzy. In: Euvres complètes, Psychanalyse, t. XX. Paris: PUF.

GREEN, A. (1988) Pourquoi le mal?. Nouvelle Revue de Psychanalyse, n.38, p.239-261.

GREEN, A. (2007) Pourquoi les pulsions de destruction ou de mort? Paris: Panama.

KAHN, L. (2005) Faire parler le destin. Paris: Klincksieck.

LÉVI, P. (1966) La trêve, trad. E. Genevois-Joly. Paris: Grasset. (Les cahiers rouges)

PUGET, J. (Eds.) (2001) Violence d'état et psychanalyse. Paris: Dunod.

VILLA F. (2009) Au cœur du rêve, la horde, penser/rêver, n.15, Toute-puissance, printemps, Paris: De l'Olivier, 41-60.

VILLA, F. \& WEIL. E. (2007) “The spirit of evil, by Nathalie Zaltzman. Paris: De l'Olivier. (Collection Penser/Rêver). 109 p. International Journal of Psychoanalysis, no prelo em 2010. 
VIÑAR M. \& M. (1989) Exil et torture. Paris: Denoël.

WEBER, M. (1904-1905/1964) L'éthique protestante et l'esprit du capitalisme, trad. J. Chavy. Paris: Plon.

WEIL, E. (2000) Silence et latence. Révue Française de Psychanalyse; 64(1): 169-179.

ZALTZMAN, N. (1998) De la guérison psychanalytique. Paris: PUF.

(2007) L'esprit du mal. Paris: De l'Olivier. (Collection Penser/ Rêver)

François Villa

villa@ univ-paris-diderot.fr 